\title{
THE PATTERNS OF INNOVATION AGENDAS ON 5G MOBILE TECHNOLOGY
}

\author{
Muhammad Suryanegara $^{1 *}$, Muhamad Asvial ${ }^{1}$ \\ ${ }^{1}$ Department of Electrical Engineering, Faculty of Engineering, Universitas Indonesia, Kampus UI \\ Depok, Depok 16424, Indonesia
}

(Received: April 2018 / Revised: May 2018 / Accepted: August 2018)

\begin{abstract}
This paper aims to map the patterns of innovation agendas for $5 \mathrm{G}$ mobile technologies by investigating the scientific research activities already related to the development of this mobile generation. To carry out this research, 380 research publications from 2009 to 2016 held in the Scopus database were utilized, from which 992 keywords were extracted and categorized into 39 innovation agendas. The numbers of documents grouped into these agendas, and the ways in which they were connected to each other, were then analyzed. The findings identify five patterns of innovation. The first contains innovation agendas related to "millimeter wave" and "energy" as the main technical issues that shape the overall profile of 5G mobile development. The second reflects that, despite $5 \mathrm{G}$ being proposed as a new communication system, it will not be entirely independent of previous technological platforms in which long-term evolution (LTE) has a strong influence on current technical innovation systems. In the third, it can be seen that some innovation agendas that deliver low productivity have in fact provided more room for those who want to be involved, and have thus opened up opportunities for science creators to actively engage with and contribute to these agendas. The fourth demonstrates that current innovation related to $5 \mathrm{G}$ is still marked by intense research activity on basic technical issues relating to wireless infrastructure. Finally, the fifth pattern indicates that there are many technical innovations being proposed, but only some will finally be utilized in a mature 5G system.
\end{abstract}

Keywords: 5G; Innovation; Mobile technology; Wireless technology

\section{INTRODUCTION}

Knowing the patterns of innovation is essential for those wishing to engage in appropriate research activities and to seize the innovation opportunities offered by new and immature technologies. As 5G mobile technology is still in its early-to-middle phase of development, it is important to portray its innovation patterns from the perspective of the science and knowledge creators who have so far contributed to the subject. Technological innovation can be regarded as the process of making a new form of technology, involving a process of generating and exchanging the knowledge relevant to its technological commercialization (Malerba, 2004). The conceptual approach used in this research is therefore that knowledge is the main ingredient of any technological innovation process. In the case of mobile technology, the essence of this paradigm relates to the way knowledge has contributed to the process of continual technical development from the first generation $(1 \mathrm{G})$ to the upcoming fifth generation $(5 \mathrm{G})$, and how the technology successfully diffuses into the market.

\footnotetext{
${ }^{*}$ Corresponding author's email: m.suryanegara@ui.ac.id, Tel. 021-7270078, Fax. 021-7270077 Permalink/DOI: https://doi.org/10.14716/ijtech.v9i5.1941
} 
In the beginning phase of $5 \mathrm{G}$ mobile technological development, the innovation opportunities were signified by identifying sets of knowledge that had been utilized in the very early development of 5G (Felita \& Suryanegara, 2013). Yet, scientific research activities producing relevant knowledge for developing $5 \mathrm{G}$ are now becoming advanced. Hence, since knowledge is the basis of innovation, it can be said that the "on-going portrayal" of the $5 \mathrm{G}$ innovation pattern is becoming established.

The significance of knowing the pattern of innovation is that it can help stakeholders in $5 \mathrm{G}$ to build the capability to grasp opportunities arising from anticipated technological innovations. In this case, the stakeholders in 5G are the researchers ("science knowledge creators"), the industry ("technology developers"), the market ("technology users"), and the regulator ("technology regulator").

The objective of this work is to identify and portray the pattern of innovation through focusing only on the theme of knowledge. This theme is characterized as the innovation agenda, since it will eventually lead to the creation of particular innovative aspects of 5G. Hence, the main contribution of this work will be for $5 \mathrm{G}$ stakeholders working to create $5 \mathrm{G}$-relevant scientific knowledge. By being conversant with patterns of innovation, stakeholders may be able to seize opportunities and strengthen their relevant capabilities for the development of 5G-technologyrelated software/hardware platforms. For example, stakeholders will be able to understand which innovation themes have the most influence, the nature of the influence of these themes, and the implications of the other themes.

This work conducts its data analysis based on a bibliometric method combined with an evolutionary theory of technological change. Scientific research documents on the Scopus database were investigated and 992 keywords were extracted and categorized into 39 innovation agendas. Further analysis was derived by looking at the number of documents which were grouped into these agendas. To support the analysis of the findings, the connections between the innovations were investigated. In this context, a Darwinian evolutionary theory is utilized to understand the nature of technological change relating to $5 \mathrm{G}$ as it adapts to changes in its environment.

The reminder of the paper is organized into sections addressing underlying theory (Section 2), method and findings (Section 3), discussion (Section 4) and the conclusions of the study (Section 5).

\section{UNDERLYING THEORY: FINDING INNOVATION PATTERNS}

There are several approaches to identifying patterns of technological innovation. A pattern may, for example, relate to the technology developers, in terms of their affiliation to particular countries, or it may focus on related knowledge themes. This work uses the latter approach, the pattern of knowledge themes, as characterized as innovation agendas.

One of the prominent methods used to identify and build up such patterns is investigation of the profile of scientific research documents, i.e. journal articles, book chapters, conference papers, etc. The logic for using this approach is derived from the common conception that scientific documents are the codified output of research activities, while research, by its nature, comprises the activities of exploring and exploiting knowledge. In summary, knowledge is the fundamental basis of any innovation, while the science creators are the main sources of knowledge which enable the development of related technologies. Hence, a technological innovation pattern could be perceived as the outcome of the robust development of scientific research activities. 
The bibliometric method is a commonly used tool in the quantitative measurement of research activities. It operates by measuring the textual information present in scientific research articles (usually journal articles), including citation data, content analysis, keyword analysis, and revealing authors' affiliations and mapping out relationships among academic publications. The applications of this method are diverse, ranging from measuring the impact of academic works through to tracing the progress of technological developments. Work related to this research includes those studies using bibliometrics to portray the technological changes from $3 \mathrm{G}$ to $4 \mathrm{G}$ mobile technologies (Suryanegara \& Miyazaki, 2010), those using bibliometric and patent analysis to forecast emerging technologies (Daim et al., 2006), and those using bibliometric methods to determine the innovation trends in the development of RFID (Chao et al., 2007). A work by (Surjandari et al., 2015) has also utilized such a method to build a research theme mapping for portraying the roadmap for country's future research policy.

\section{METHODS AND FINDINGS}

In this study, the bibliometric method is used to reveal text information relating to research activities in technological developments relating to $5 \mathrm{G}$. Basically, such a method is statistical analysis of codified knowledge in any means of literatures documents, such as books, journal articles, and conference papers. This method can be further exploited by combining with any data mining algorithm, for example k-Means algorithm may be used to measure similarities and differences among documents. To open a room for future study, this current paper only utilizes the bibliometric method without approaching data mining algorithm. We develop the threesteps-procedure to generate the pattern of innovation as follows.

\subsection{Step 1: Collecting Scientific Documents from the Scopus Database}

The first step was to build profile analyses of scientific research articles, by collecting relevant scientific publications in English from Scopus. Scopus is a database which aggregates scientific articles from the leading scientific and engineering journals (IEEE publications, ETRI, Elsevier, Hindawi, Inderscience, Wiley, etc.).

The basis of the selection was the extraction of documents containing the words " $5 \mathrm{G}$ " and "wireless", either in their titles, abstracts, or keywords. Such queries identified a total of 2,559 documents that could be regarded as scientific articles related to $5 \mathrm{G}$ in the Scopus database, published between the early 2000s (when references to 5G first appeared) and 2016.

The sampling mechanism was refined by adding the text, "fifth generation". This term is used as a specialist search string identifying authors' statements that their work contributes to overcoming the limitations of "fourth generation" technology. Altogether, 410 documents published between 2009 and 2016 were obtained, consisting of 229 conference papers, 160 journal articles, 15 review articles and six book chapters. This research argues that these documents are a valid sample, representing the total number of scientific articles related to $5 \mathrm{G}$ in the Scopus database.

To ensure the comparable merit of the articles, documents were further cleansed, leaving a total of 380 documents. This cleansing mechanism excluded second appearances of articles that were published in conference proceedings as well as in journals, and articles in which the abstracts were written in English but the body of the article was in another language.

\subsection{Step 2: Categorizing into Innovation Agendas based on Keywords}

The 380 articles were categorized based on their stated keywords. The keywords used in this research are those believed to best reflect the "innovation theme" claimed by the author(s) of the articles, and the general ideas of the innovator. From the 380 papers, 992 unique keywords were obtained. The most-used keywords were "5G" and "network", and these were ignored in further analysis because they are too general to provide significant profiles for discussion. Apart 
from these two terms, the keywords obtained were grouped into 39 categories, the so called "innovation agendas".

Table 1 List of innovation agendas, numbers of documents and their keywords

\begin{tabular}{|c|c|}
\hline $\begin{array}{l}\mathrm{No} \\
{[1]}\end{array}$ & $\begin{array}{c}\text { Keywords (some examples) } \\
{[3]}\end{array}$ \\
\hline $\begin{array}{ll}1 & \begin{array}{l}\text { Millimeter wave (mm wave) - } 106 \\
\text { documents }\end{array} \\
\end{array}$ & $\begin{array}{l}\text { Millimeter-wave communications, millimeter-wave, } \\
\text { mm-wave, high frequency band, submillimeter wave, }\end{array}$ \\
\hline Energy - 84 documents & Energy detection, energy dissipation, energy efficiency, \\
\hline Antenna - 77 documents & $\begin{array}{l}\text { Antenna beam width, antenna structures, antenna tilting, } \\
\text { fractal antenna }\end{array}$ \\
\hline MIMO - 68 documents & Massive MIMO, MIMO channel model, MIMO systems \\
\hline Heterogeneous - 62 documents & $\begin{array}{l}\text { Heterogeneous access, heterogeneous network (Het- } \\
\text { Net), heterogeneous traffic }\end{array}$ \\
\hline Interference - 59 documents & $\begin{array}{l}\text { Aggregate interference, co-channel interference, } \\
\text { interference cancellation, }\end{array}$ \\
\hline LTE - 49 documents & LTE, LTE schedulers, LTE-A, LTE-U, 4G/LTE \\
\hline Power control - 46 documents & $\begin{array}{l}\text { Average power, average power constraint, linear power } \\
\text { amplifier, low power electronics }\end{array}$ \\
\hline Optimization - 41 documents & $\begin{array}{l}\text { Constraint optimization, cross-layer optimization, } \\
\text { network optimization }\end{array}$ \\
\hline 10 Quality of Service - 36 documents & QoS, quality of service \\
\hline 11 OFDM - 36 documents & $\begin{array}{l}\text { OFDM, frequency division multiplexing, GFDM, } \\
\text { OFDMA }\end{array}$ \\
\hline 12 Spectrum efficiencies - 34 documents & $\begin{array}{l}\text { Spectral efficiencies, spectrum efficiency, high spectral } \\
\text { efficiency }\end{array}$ \\
\hline 13 Error correction and coding - 32 & $\begin{array}{l}\text { Binary code, channel coding, error correction, turbo } \\
\text { codes, network coding }\end{array}$ \\
\hline 14 Security - 29 documents & 5G security, mobile security, end-to-end security \\
\hline 15 IoT (Internet of Things) - 23 & $\begin{array}{l}\text { Internet of things, Internet of everything, IoT, device-to- } \\
\text { device communications }\end{array}$ \\
\hline 16 Cognitive network - 22 documents & Cognitive network, cognitive radio, cognitive system \\
\hline 17 Resource allocation - 21 documents & Resource allocation schemes, Radio resource allocation \\
\hline 18 Cost - 19 documents & $\begin{array}{l}\text { Cost effectiveness, cost function, cost minimization } \\
\text { planning }\end{array}$ \\
\hline 19 Beamforming - 17 documents & $\begin{array}{l}\text { Analog beamforming, directional beamforming, antenna } \\
\text { beamforming }\end{array}$ \\
\hline $20 \begin{array}{l}\text { Distributed computer system - } 17 \\
\text { documents }\end{array}$ & Distributed computer systems \\
\hline 21 Virtualization - 14 documents & $\begin{array}{l}\text { Virtualization, network function virtualization (NFV), } \\
\text { NFV and SDN }\end{array}$ \\
\hline 22 Intelligent Systems - 13 documents & $\begin{array}{l}\text { Intelligent systems, intelligent buildings, intelligent } \\
\text { transport systems, network intelligence }\end{array}$ \\
\hline 23 Virtual reality - 13 documents & Virtual reality \\
\hline 24 Multiuser detection - 12 documents & $\begin{array}{l}\text { Multiuser detection, multiuser environment, multi-user } \\
\text { detection scheme }\end{array}$ \\
\hline 25 Cloud computing - 12 documents & Cloud computing, mobile cloud computing \\
\hline 26 Balloons - 10 documents & Balloons \\
\hline 27 Scheduling - 9 documents & Scheduling, scheduling discipline, resource-scheduling \\
\hline 28 CRAN - 8 documents & $\begin{array}{l}\text { Cloud radio access network (C-RAN), cloud RAN, } \\
\text { CRAN, C-RAN, }\end{array}$ \\
\hline 29 Quality of experience -8 documents & QoE, quality of experience, \\
\hline
\end{tabular}




\begin{tabular}{lll}
\hline $\begin{array}{c}\text { No } \\
{[1]}\end{array}$ & $\begin{array}{c}\text { Innovation agendas and Number of } \\
\text { documents [2] }\end{array}$ & \multicolumn{1}{c}{$\begin{array}{c}\text { Keywords (some examples) } \\
{[3]}\end{array}$} \\
\hline 30 & $\begin{array}{l}\text { Visible light communications - } 7 \\
\text { documents }\end{array}$ & $\begin{array}{l}\text { Visible light communications, VLC, visible light } \\
\text { communication }\end{array}$ \\
\hline 31 & FBMC - 7 documents & FBMC, FBMC/OQAM \\
\hline 32 & WLAN - 6 documents & WLAN, wireless local networks, WLAN offload, etc. \\
\hline 33 & Big data - 6 documents & Big data \\
\hline 34 & Femtocell - 6 documents & Femtocell, femto-cells, femtocell networks \\
\hline 35 & NOMA - 6 documents & $\begin{array}{l}\text { NOMA, non-orthogonal multiple access, nonorthogonal } \\
\text { multiple access, (NOMA) }\end{array}$ \\
& & $\begin{array}{l}\text { Software defined network, software-defined networking, } \\
\text { SDN, NFV and SDN, }\end{array}$ \\
\hline 36 & $\begin{array}{l}\text { Software-defined network (SDN) - 6 } \\
\text { documents }\end{array}$ & SCMA, sparse code multiple access (SCMA) \\
\hline 37 & SCMA - 5 documents & High speed railways, railroad engineering, railways \\
\hline 38 & $\begin{array}{l}\text { Railway communications - 5 } \\
\text { documents }\end{array}$ & E-band, E-bands \\
\hline 39 & E-band - 3 documents & \\
\hline
\end{tabular}

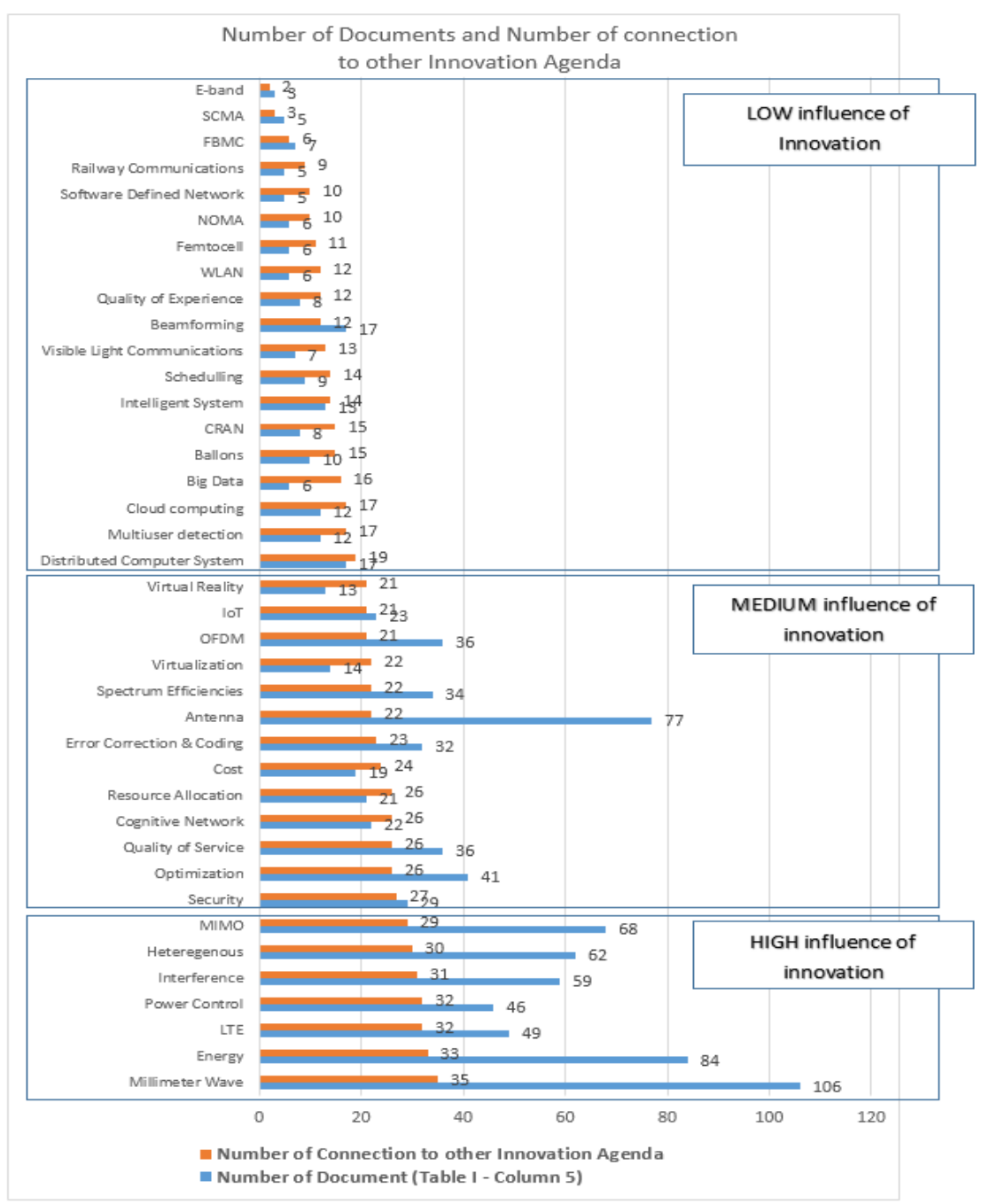

Figure 1 Number of documents and number of connections to other innovation agendas

The complete list of 39 innovation agendas is presented in Table 1. The innovation agendas and their number of documents that contain each keyword are listed in column [2], while column 
[3] gives the corresponding keywords (out of the 992 unique keywords). The values from this column being represented by the blue graphic bars in the Figure 1.

Table 1 shows that the millimeter wave innovation agenda contains the greatest number of papers. It is followed by the innovation agendas energy and antenna. The least number of documents is found in the E-band innovation agenda that deals with technical operations at the frequency band between 60 and $90 \mathrm{GHz}$.

There are general objectives of the research activities of each agenda, explaining how the agenda is developed to achieve innovation relating to the particular objective. For example, the documents grouped in the innovation agenda for millimeter wave are the output of research activities aimed to deliver $5 \mathrm{G}$ over the millimeter wave frequency band from 30-300 GHz. The orientation of this theme relates to ways in which innovations can be established to provide communications at a very high speed over a much larger bandwidth than previously possible.

\subsection{Step 3: Identifying the Number of Connections between Innovation Agendas}

Step 3 is built by utilizing the perspective of evolutionary theory (Dosi \& Nelson, 1994), (Nelson, 1994). The evolutionary theory of technological change has developed from the Darwinian mechanism of survival and change through learning, adaptation, and variation. A living organism will learn about its environment then develop mechanisms of adaptation through mutation. Similarly, any technological innovation needs to learn from its environment and make appropriate adaptation in order to survive. In this paper it is argued that such learning mechanisms in technology are influenced by the profile of an innovation's connections with other innovations. The more innovations are connected, the more they co-evolve and strengthen the innovation, by creating adaptations to changes in the environment.

In step 3, the numbers of connections between the 39 innovation agendas are identified by looking at the co-occurrence of keywords. Typically, one document has up to five keywords, and as a result, one document can be categorized into several innovation agendas. The aggregate value of those categorizations is the number of connections between one innovation agenda and another. This number is represented by the blue graphical bar in Figure 1.

For example, Figure 1 shows that the millimeter wave innovation agenda has 35 connections (shown by the red bar) and is mentioned in 106 documents (blue bar). These values indicate that 106 documents are categorized as referring to the millimeter wave innovation agenda, and that these 106 documents can be categorized into 35 other innovation agendas with which they share keywords. This indicates that the millimeter wave innovation agenda has influences on these 35 other innovation agendas. An illustration of this condition is shown in Figure 2.

This phenomenon of co-occurrence indicates a common presence of keywords in a single technological system. The greater the number of connections, the greater the strength of an innovation agenda in its influence on those connected agendas. Based on the number of connections the agendas have been grouped accordingly into three innovation influence levels, namely high, i.e. connects to 29-35 agendas; medium, i.e. connects to 20-27 agendas; and low, i.e. connects to 2-19 agendas. Figure 1 shows that the high innovation influence group consists of the millimeter wave, energy, LTE, power control, interference, heterogeneous network, and $M I M O$ innovation agendas.

The millimeter wave innovation agenda has the highest innovation influence and consequently it can be said to act as the inspiration focus of the $5 \mathrm{G}$ innovation process, since almost the entire range of innovation agendas include it. Interestingly, this is not the case for the antenna innovation agenda. Although the number of documents featuring antenna-related terms (77) is the third most frequent, the number of connections for the agenda is only 22 , thus categorizing 
it as of medium influence. This suggests that the antenna innovation agenda does not affect other areas of innovation as greatly as does the millimeter wave agenda.

\section{DISCUSSION OF PATTERNS OF INNOVATION}

The following discussions are derived from the main findings represented in Table 1 and Figure 1 .

\subsection{Pattern 1: The millimeter wave and energy Innovation Agendas are the Main Sources of Innovation for $5 \mathrm{G}$}

The findings presented in Table 1 show that the millimeter wave innovation agenda contains the largest number of documents (106), followed by the energy innovation agenda (84). These values clearly indicate that research activities to develop 5G mobile communications are heavily oriented toward delivering communications platforms in the millimeter wave spectrum band, and toward achieving energy efficiency.

As shown in Figures 2 and 3, the research also identifies these two agendas as the main sources of innovation, as they have the most connections to other innovation agendas. Research activities related to millimeter waves are connected to 35 other research areas, while the topic of energy is connected to 33 research areas. Thus it can be seen that both have inspired almost all of the research areas. Figures 2 and 3 identifies these connections.

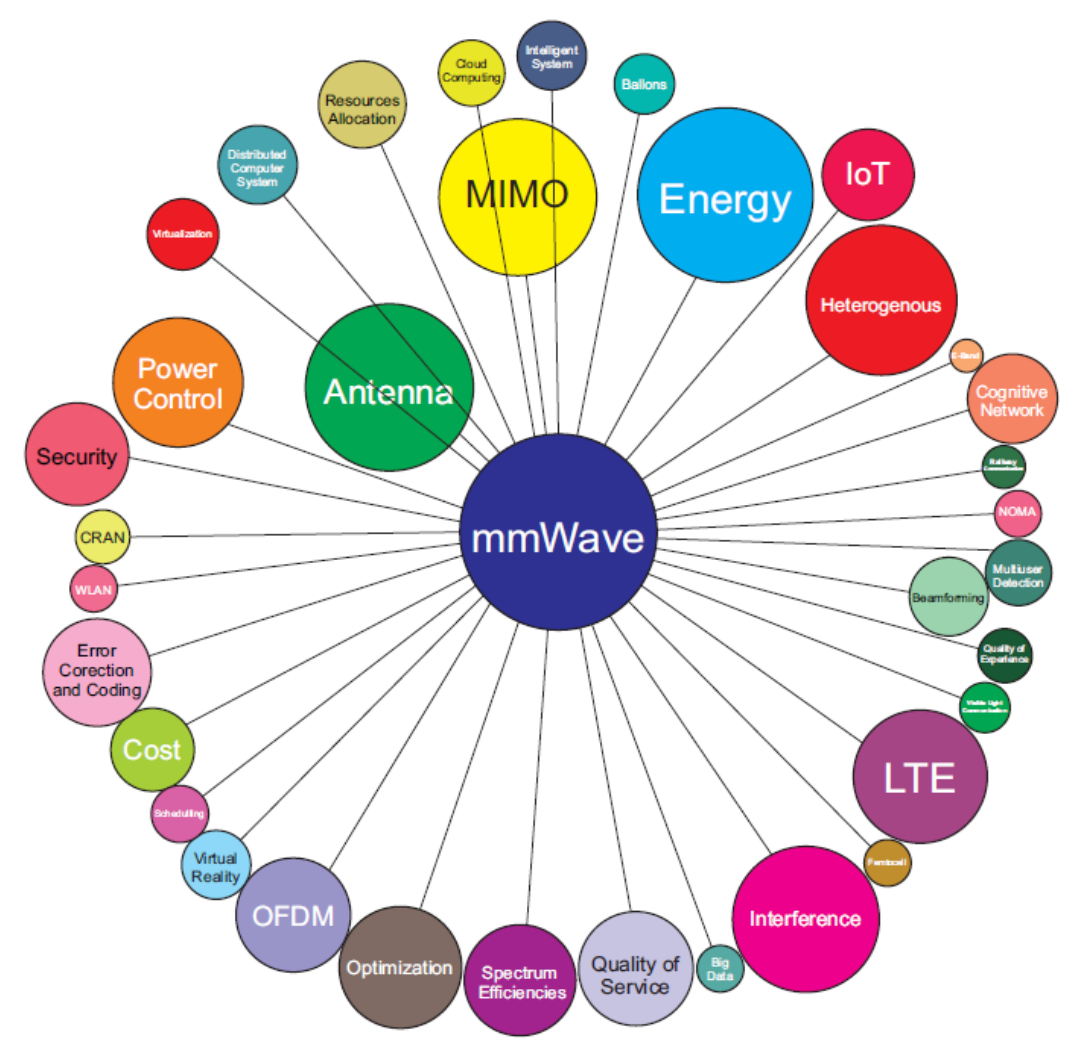

Figure 2 The influence of the millimeter wave innovation agenda on 35 other agendas

Looked at from the perspective of type of innovation, the millimeter wave and energy agendas can be regarded as forms of disruptive innovation, i.e. innovations that offer very different attributes to those of existing mainstream technologies. The main technical profile of $5 \mathrm{G}$ is that RF equipment access will operate over the millimeter waveband, and will have very different attributes from the mainstream cellular generations ( $3 \mathrm{G}$ and $4 \mathrm{G})$. 


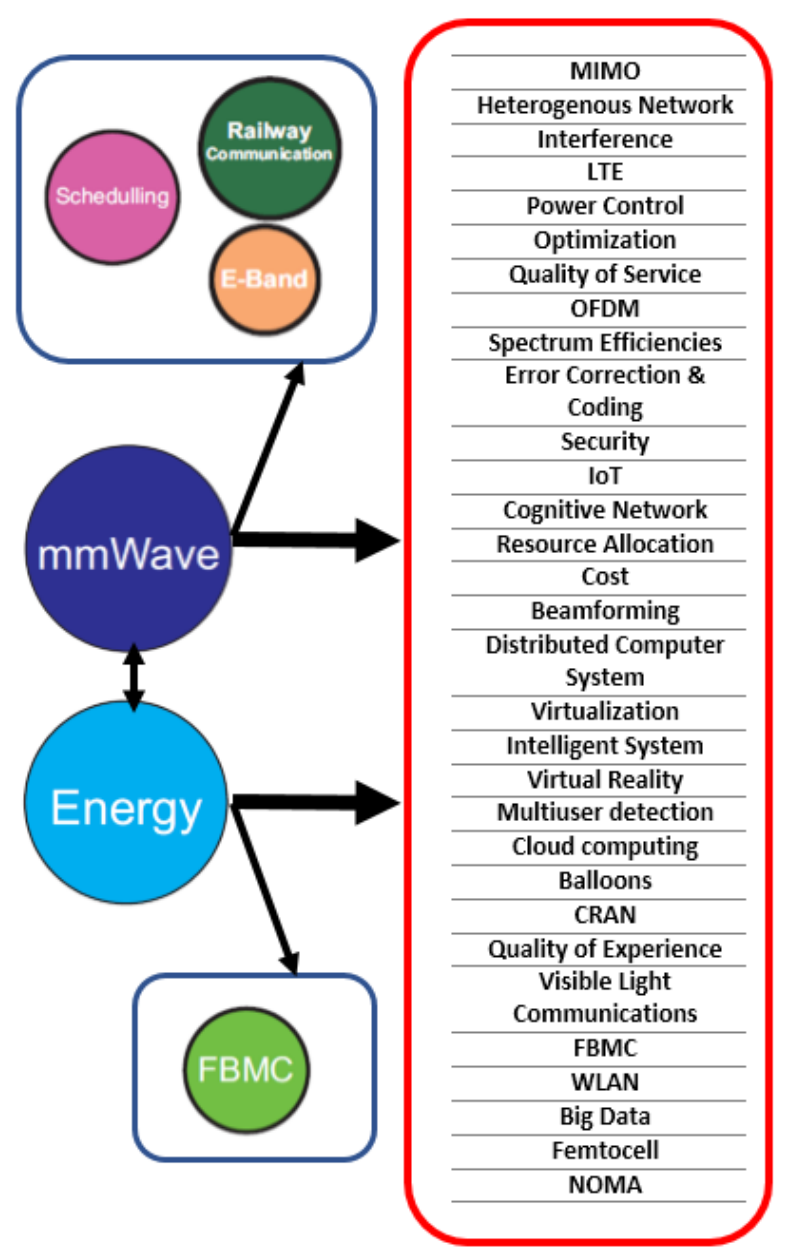

Figure 3 Millimeter wave and energy innovation agendas as the main sources of innovation in 5G development

In addition, these agendas were hardly discussed in preceding generations of mobile technology, with the research topic of CDMA dominating $3 \mathrm{G}$ development, and the data communications agenda dominating 4G development (Suryanegara \& Miyazaki, 2010).

As 5G will deliver a high-speed data rate, its requirements for larger bandwidth and smaller coverage will only be satisfied by utilizing operations in the millimeter waveband. This kind of research activity has led to the authorized spectrum band now being close to coming under regulation by International Telecommunications Union (ITU, 2016). In the World Radiocommunications Conference 2019 (WRC-19), the allocations of 5G spectrum bands will be officially decided, with the specific bands to be considered being $24.25-27.5 \mathrm{GHz}, 31.8-$ $33.4 \mathrm{GHz}, 37-43.5 \mathrm{GHz}, 45.5-50.2 \mathrm{GHz}, 50.4-52.6 \mathrm{GHz}, 66-76 \mathrm{GHz}$, and 81-86 GHz (GSMA, 2016).

An example of how the millimeter wave agenda has inspired the other innovation agendas can be observed by considering its connections with the antenna and femtocell innovation agendas. Prominent topics in research activities are millimeter wave channel measurements and modeling for indoor femtocell applications (Moraitis \& Panagopoulus, 2015).

In respect of the energy agenda, analysis can be based on the example of the three crucial capability scenarios for 5G technology, i.e. considerably higher network capacity, service of massive device connectivity, and service with low latency, with all of these achieving considerable energy savings compared to existing wireless technologies (Abdelwahab et al., 
2016). Thus, a need to reduce energy consumption has become the main issue motivating almost all other research areas.

Another example is the connection between the energy innovation agenda and the IoT and security agendas. In terms of 5G, IoT-related technology refers to the $5 \mathrm{G}$ service plan for massive machine-to-machine communications. One of the prominent research topics is the security of IoT platforms. Although the IoT has lower energy consumption than existing technologies, the task of ensuring security and privacy is challenging (Trappe et al., 2015).

Figure 3 shows that, despite their role as main sources of innovation, neither the millimeter wave nor the energy agendas influence the scheduling, railway communications and E-band agendas while the millimeter wave agenda does not influence FBMC.

\subsection{Pattern 2: 5G Innovations are not Independent of Previous Technological Platform}

The second pattern identified indicates that $5 \mathrm{G}$ developments are not independent of the technology of the preceding platform. The frequency of several innovation agendas which also relate to $4 \mathrm{G}$ technology development can be seen in Table 1, for example MIMO (68 documents), OFDM (36 documents), and LTE (49 documents). Research activities strongly related to $M I M O$ were conducted during $4 \mathrm{G}$ development and are now becoming important in the development of $5 \mathrm{G}$; a similar phenomenon applies to OFDM and LTE.

Interestingly, there are relatively few documents that can be categorized into the WLAN innovation agenda. Like LTE, WLAN is considered as a feature of the previous technological platform, but only six documents include it in their keywords, compared to 49 documents for LTE. This clearly implies that $5 \mathrm{G}$ infrastructure will be a continuation of the existing LTE network, but not of other network platforms. In another words, 5G may be built on underlying LTE infrastructure but not on WLAN. In support of this finding, 3GPP (the organization which developed/supports LTE) has set a target of LTE Release 15 being the first set of 5G standards.

\subsection{Pattern 3: There are Research and Development Opportunities in Some of the Innovation Agendas}

Table 1 indicates that there are several innovation agendas considered as frontier knowledge areas of $5 \mathrm{G}$ in which there are still substantial issues and problems to be researched. They include, among others, the IoT, CRAN, virtualization, SDN, and virtual reality agendas. Figure 4 indicates that the IoT innovation agenda contains 23 documents connected to 21 other innovation agendas, thus research into IoT service applications may also influence many other research activities. This suggests that research related to the IoT is inclusive of other important aspects of 5G development and so may have impacts on other areas.

It is important to note the number of research activities with low numbers of mentions appearing within the medium innovation influence category. The IoT, virtualization, software defined network $(S D N)$, and virtual reality agendas are also regarded as disruptive innovations, but in the eras of $3 \mathrm{G}$ and $4 \mathrm{G}$ there were very few research activities on these themes. It is clear from these observations that the arenas for innovation are wide and contain windows of opportunity that scientific creators may utilize in order to conduct many related research activities. 


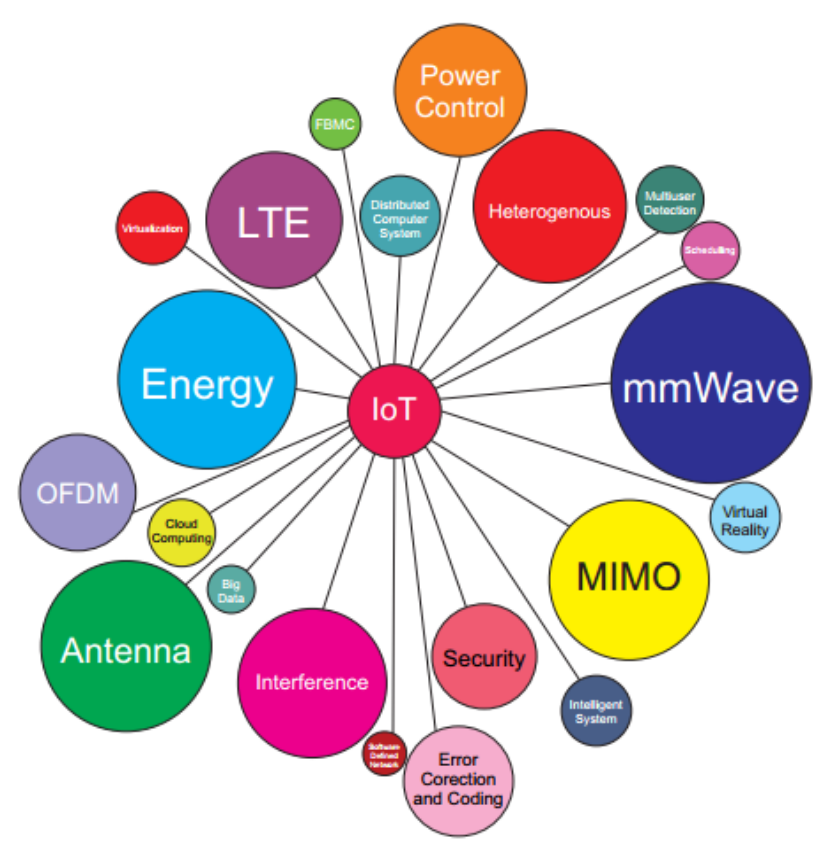

Figure 4 The IoT innovation agenda and its connections with 21 other innovation agendas

Countries can take advantage of technological agendas that are still growing and can develop cooperation between technologies. Technology moves dynamically and so requires interrelationships between platforms. It is in these relationships that scholars can enter into, and contribute to, the development of knowledge.

Table 1 reveals that the antenna and power control innovation agendas contain a large proportion of the total documents (77 and 46, respectively). Both of these innovation agendas are considered as basic technical issues in any wireless infrastructure that need to be developed as sources of knowledge for new generations of any wireless technology, including 5G.

As shown in Figure 2, it is interesting to note that the antenna research activity is quite "exclusive", as its 77 documents only connect to 22 other agendas. The nature of research activities about antenna is that they tend to limit their activities to central hardware and technical issues. It is evident that connections between antenna and non-technical innovation agendas such as cost and quality of experience are rare.

\subsection{Pattern 4: Intense Research Activity on Basic Technical Issues Relating to Wireless Infrastructure}

Some other basic technical issues relating to wireless infrastructure are also revealed in Table 1. These include interference, power control, error correction and coding, resource allocation and beamforming. From a wider perspective, we can say that innovation relating to $5 \mathrm{G}$ has so far focused exclusively on technical infrastructure issues. A prominent example is the technology related to network slicing which has been recently emerged (Foukas et al., 2017; Zhang et al., 2017).

This phenomenon is in line with the finding of this study that numbers of IoT-related research activities are not sufficient. The number of IoT-related documents is only 23 (out of 380 documents), and this indicates that science creators have assumed $5 \mathrm{G}$ innovation is more related to its network infrastructure rather than to service applications. However, while 5G scenarios will support massive-machine-to-machine communication (Palattella et al., 2016), IoT is merely an application not specifically designed for the upcoming emergence of 5G. In fact, any IoT service can run over the $3 \mathrm{G}$ and $4 \mathrm{G}$ networks, and other connectivity platforms. 


\subsection{Pattern 5: Innovations have been Proposed, but only Some Likely to Survive}

There are some research activities which raise new and challenging topics, such as NOMA, FBMC, SCMA, E-band and visible light communications. The presence of these activities in the research documents indicates that the process of $5 \mathrm{G}$ innovation has, up to this point, opened up the willingness of science creators to propose some new paradigms, technologies, and even technical platforms.

There are innovation agendas that seem to fall outside the mainstream technical topics, such as railway communications and balloon. Such issues may reflect the platform's levels of capability for dealing with socioeconomic challenges. For example, a work has envisioned a $5 \mathrm{G}$ network for rural and low-income zones utilizing high-altitude balloons (Chiaraviglio et al., 2016). Meanwhile, the research activities on railways look at the utilization of the $5 \mathrm{G}$ network on railway services.

However, technological innovations need to survive in changing environments. As explained in Section 3.2, evolutionary theory states that innovations in nature need to learn from the environment and to adapt to it. In this study, the mechanism of learning is represented by connections between innovation agendas. The more an agenda is connected with others, the more they can co-evolve and build on technical adaptations. Hence, it is argued that only an innovation that has significant connections with other agendas will survive. In summary, there are many technical innovations being proposed, but only some will be finally utilized in a mature $5 \mathrm{G}$ system.

\section{CONCLUSION}

This work has identified the patterns of innovation in 5G-related research activities. The 380 relevant published documents from the Scopus database between 2009 and 2016 were mapped, and from these 992 keywords were extracted and categorized into 39 innovation agendas. The analysis is based on the number of documents which fall into each agenda, and the connections among them.

The findings have indicated patterns of innovation: First, the innovation agendas related to millimeter wave and energy are the main sources of innovation that shape the entire profile of 5G development. Second, despite 5G being proposed as a new communications system, the previous technological platforms are still having a substantial influence on current technical innovation. Third, some innovation agendas currently sparsely represented in the publications open up opportunities for science and technology creators to actively engage in research activities. Fourth, current innovations relating to $5 \mathrm{G}$ are still marked by intense research activities around the basic technical issues of wireless infrastructure. This indicates that science creators are working heavily to make innovations in network infrastructure rather than in service application. Fifth, there are many technical innovations being proposed, but only some of these will be finally utilized in a mature 5G system. The more an agenda has connections with others, the more they co-evolve and create technical adaptations. Only an innovation that has significant connections with other agendas likely to survive.

\section{ACKNOWLEDGEMENT}

This research is funded by Hibah PDUPT 2018 Ministry of Research and Technology and Higher Education Republic of Indonesia. This article's publication is supported by the United States Agency for International Development (USAID) through the Sustainable Higher Education Research Alliance (SHERA) Program for Universitas Indonesia's Scientific Modeling, Application, Research, and Training for City-centered Innovation and Technology (SMART CITY) Project, Grant \#AID-497-A-1600004, Sub Grant \#IIE-00000078-UI-1. 


\section{REFERENCES}

Abdelwahab, S., Hamdaoui, B., Guizani, M., Znati, T., 2016. Network Function Virtualization in 5G. IEEE Communications Magazine, Volume 54(4), pp. 84-91

Chao, C.C., Yang, J.M., Jen, W.Y., 2007. Determining Technology Trends and Forecasts of RFID by a Historical Review and Bibliometric Analysis from 1991 to 2005. Technovation, Volume 27(5), pp. 268-279

Chiaraviglio, L., Blefari-Melazzi, N., Liu, W., Gutierrez, J.A., Van De Beek, J., Birke, R., Chen, L., Idzikowski, F., Kilper, D., Monti, J.P., Wu, J., 2016. 5G in Rural and Lowincome Areas: Are We Ready? In: Proceedings of ITU Kaleidoscope: ICTs for a Sustainable World, 14-16 November 2016, Bangkok, Thailand, pp. 1-8

Daim, T.U., Rueda, G., Martin, H., Gerdsri, P., 2006. Forecasting Emerging Technologies: Use of Bibliometrics and Patent Analysis. Technological Forecasting and Social Change, Volume 73(8), pp. 981-1012

Dosi, G., Nelson, R.R., 1994. An Introduction to Evolutionary Theories in Economics. Journal of Evolutionary Economics, Volume 4(3), pp. 153-172

Felita, C., Suryanegara, M., 2013. 5G Key Technologies: Identifying Innovation Opportunity. In: Proceedings of $13^{\text {th }}$ International Conference on Quality in Research (QiR), Yogyakarta, Indonesia, 25-28 June 2013, Yogyakarta, Indonesia, pp. 235-238

Foukas, X., Patounas, G., Elmokashfi, A., Marina, M.K., 2017. Network Slicing in 5G: Survey and Challenges. IEEE Communications Magazine, Volume 55(5), pp. 94-100

GSMA, 2016. 5G Spectrum Public Policy Position. Available online at https://www.gsma.com/spectrum/wp-content/uploads/2016/06/GSMA-5G-SpectrumPPP.pdf

International Telecommunications Union (ITU), 2016. ITU, ITU-T P.10/G.100, Amendment 5: New Definitions for Inclusion in Recommendation ITU-T P.10G.100. Available online at www.itu.int

Malerba, F., 2004. Chapter 14: Sectoral System, How and Why Innovation Differs across Sectors. The Oxford Handbook of Innovation. Oxford University Press, The University of Oxford, England

Moraitis, N., Panagopoulos, A.D., 2015. Millimeter Wave Channel Measurements and Modeling for Indoor Femtocell Applications. In: Proceedings of the $9^{\text {th }}$ European Conference on Antennas and Propagation, 12-17 April 2015, Lisbon, Portugal, pp. 1-6

Nelson, R.R., 1994. The Co-evolution of Technology, Industrial Structure, and Supporting Institutions. Industrial and Corporate Change, Volume 3(1), pp. 47-63

Palattella, M. R., Dohler, M., Grieco, A., Rizzo, G., Torsner, J., Engel, T., Ladid, L., 2016. Internet of Things in the 5G Era: Enablers, Architecture, and Business Models. IEEE Journal on Selected Areas in Communications, Volume 34(3), pp. 510-527

Suryanegara, M., Miyazaki, K., 2010. Technological Changes in the Innovation System towards 4G Mobile Service. International Journal of Technology Policy and Management, Volume 10(4), pp. 375-394

Surjandari, I., Dhini, A., Lumbantobing, E.W.I., Widari, A.T., Prawiradinata, I., 2015. Big Data Analysis of Indonesian Scholars' Publications: A Research Theme Mapping. International Journal of Technology, Volume 6(4), pp. 650-658

Trappe, W., Howard, R., Moore, R.S., 2015. Low-energy Security: Limits and Opportunities in the Internet of Things. IEEE Security Privacy, Volume 13(1), pp. 14-21

Zhang, H., Liu, N., Chu, X., Long, K., Aghvami, A.H., Leung, V.C., 2017. Network Slicing Based 5G and Future Mobile Networks: Mobility, Resource Management, and Challenges. IEEE Communications Magazine, Volume 55(8), pp.138-145 